\title{
CAPSAICIN EFFECTS ON BLINKING
}

\author{
Fidias E. Leon-Sarmiento ${ }^{1,2}$, Jaime Bayona-Prieto', Marta E. Leon-S3
}

\begin{abstract}
Blinking is a normal human phenomenom involving trigeminal and facial patways. To gain understanding on the neurobiology of blinking, five normal subjects were investigated before and after a $p$ plication of transdermal capsaicin at the forehead for two weeks. No effects of topical capsaicin were detected in eye blink rates. However, when capsaicin was applied to a female subject with blepharospasm, she showed a dramatic restoration of her vision subsequent to blinking modification. Deactivation of abnormal A-to-C fibers cross talks at the trigeminal-facial pathways seems to be the most likely mechanism of such improvement.
\end{abstract}

KEY WORDS: capsaicin, visuomotor integration, C-fibers, blinking, dystonia.

\section{Efectos de la capsaicina en el parpadeo}

RESUMEN - El parpadeo es un fenómeno normal en los humanos que involucra las vías trigéminas faciales. Con el fin de conocer un poco más la neurobiología de este fenómeno estudiamos cinco individuos normales antes y después de aplicar capsaicina trasdérmica en la frente de cada uno de ellos, por dos semanas. La frecuencia de parpadeo no se alteró con la aplicación de capsaicina tópica. Sin embargo, cuando la misma sustancia se aplicó a una paciente con blefaroespasmo hubo dramática restauración de su visión, la cual fue secundaria a la modificación de la actividad muscular palpebral. La desactivación del cruce patológico de información que pasa de las fibras $A$ a las fibras $C$, pertenecientes a las vías trigémino-faciales, parece ser el mecanismo de acción relacionado con la aplicación de capsaicina, el que estaría directamente relacionado con la recuperación clínica observada en la paciente con blefaroespasmo.

PALABRAS CLAVES: capsaicina, integración visuomotora, fibras C, parpadeo, distonía.

Blinking keeps the cornea with moisture continuously ${ }^{1}$ and reflects activity of dopaminergic system ${ }^{2}$. In normal adult people, spontaneous eye blinking occurs 10 to 20 times per minute in a relaxed state without gender differences ${ }^{1,2}$. Different psychological conditions, psychophysics factors as well as some disorders may decrease or increase blinking such as focal dystonia. Blepharospasm, a form of focal dystonia, characterized by repetitive involuntary sustained contractions of the orbiculari oculi muscles, results in episodic eye closure and typical blinking changes.

Blepharospasm's etiology is unknown. Some reports have pointed out the possibility that noxious repeated afferent inputs produce input-output i mbalance of eye movements mediated by alpha and gamma motoneuron $\mathrm{s}^{3-5}$. Recent neurophysiologic studies also suggested that such imbalance might be due to an affe rent $A$ to $C$ fibers misconnection at supraspinal levels recorded as abnormal nocicep- tive (R2) and ultra-nociceptive (R3) responses of the blink reflex ${ }^{6,7}$.

Several interventions have been tried in blepharospasm with varying success including a recent report on the use of nicotine in one patient with such neurological disorder ${ }^{8}$. Nicotine modifies supraspinal sensory-motor integration and the ultranociceptive response (R3) of the electrically elicited blink reflex in a similar way as topical capsaicin and the like does ${ }^{9-11}$. These neurobiological similarities p rompted us to know the effects, if any, of transd e rmal capsaicin on blinking in normal or affected people with focal dystonia (e.g., blepharospasm), which might give us more clues to understand supraspinal sensory-motor processing in humans.

\section{METHOD}

Five subjects ( 3 female, 2 male; mean age $51.6 \pm 2.3$ ) with intact supraspinal sensory-motor integration gave written consent and participated in this study. None of

${ }^{1}$ G rupo Neuro.net - Instituto de Neurología Clínica y Funcional, Neurociencias Aplicadas \& Neurobiología Humana, Facultad de Salud, Universidad de Pamplona, Pamplona, Colombia; ${ }^{2}$ Profesor de Neurología Clínica y Fisiología, UIS (1996-2000), Bucaramanga, Colombia; ${ }^{3}$ División de Farmacoeconomía, INRI del Oriente, Bucaramanga, Colombia.

Received 27 January 2005, received in final form 22 April 2005. Accepted 23 May 2005.

Dr. Fidias E. Leon-Sarmiento, MD, PhD - Unidad de Trastornos del Movimiento y Neuromagnetismo, Neuro.net, Calle 74 No. 15-15 (201), Bogota Colombia. E-mail: feleoness@yahoo.com 
them received economical compensation for being part of this investigation. Capsaicin patches were worn over the forehead from $6 \mathrm{pm}$ to 6 am daily for two weeks. Eye blink rate was determined in closed room noise-isolated; the subjects were sat in comfortable position and relaxed as much as possible, they were instructed not to talk during the measurement and keeping the eyes open. The measurements were taken while they were looking a white wall for a 5 min-period as described elsewhere'. Blinking was measured before and at 3, 6, 9 and 12 hours after capsaicin application every day for two weeks. The mean of the total blinking obtained before patch application was compared against the mean value obtained after intervention using chi square; significant $p$ value was set at 0.05 .

In order to know if the neurobiological results obtained from normal volunteers paralleled people's data with some forms of supraspinal sensorimotor disintegration such as blepharospasm, we applied capsaicin patches to a 57 years old Colombian woman who had this neurological condition. Her clinical picture started one year before consultation which was prog ressing until lead her to a complete dissability of dayly life activies. She had never received medications for her symptoms including botulinum toxin treatment. The patches were worn over her forehead from $6 \mathrm{pm}$ to 6 am daily for two weeks, and a visual restoration scale similar to the one used in previous reports ${ }^{8}$ was constructed asking the patient to read a newspaper for at least 3 minutes $^{12}$. at every visit. Since the blinking rate does not reflect the severity of blepharospasm, we applied the severity rating scale (SRS) before and after interventions ${ }^{13}$ to measure clinical progression. At two weeks of intervention the patient described improvement in her vision subsequent to blinking changes reflected in the SRS. After that, we applied the patches every other day for another two weeks. Since the patient's vision continued improving the patches we re applied every third day for two weeks and, finally, every sixth day for two weeks and half during 24 hours each. The patient was followed-up for a six-month period similarly as done elsewhere ${ }^{8}$.

Table. Percentage restoration (\%) of vision after application of transdermal capsaicin in a subject with blepharospasm. 0 : unable to read at all, 100: able to read for 3 minutes ${ }^{12}$.

\begin{tabular}{lcc}
\hline Time & $\%$ & SRS $^{13}$ \\
\hline Treatment onset & $0-10$ & 4 \\
2 weeks & $20-30$ & 3 \\
4 weeks & $40-50$ & 3 \\
6 weeks & 50 & 2 \\
8 weeks and half & $80-90$ & 1 \\
Six months follow-up & $90-100$ & 1 \\
\hline
\end{tabular}

\section{RESULTS}

The blink rate in normal people was $17 \pm 3$ before intervention vs $15 \pm 5$ after application of topical capsaicin; thus, there was no significant modification on eye blinking in normal volunteers receiving capsaicin patches during 12 hours daily for two weeks. However, transdermal capsaicin produced in the subject with blepharospasm gradual improvement of clinical symptoms reaching almost complete restoration of vision at the end of six-months of follow-up (Table).

\section{DISCUSSION}

Loss of nigrostriatal dopaminergic cells decreases blink rate (e.g., Parkinson disease) and hypersensitivity of central dopamine system increases it (e.g., schizophrenia) ${ }^{2}$. There $f$ ore, the absence of capsaicin effects in blinking of normal people as observed here is in line with the dopamine influence on it in similar populations ${ }^{2}$. It should be remembered that dopamine modulates significantly the electrically elicited non-nociceptive (R1) and nociceptive (R2) blink reflex responses which have to do with spontaneous but not with forceful blinking 6, 14 . M o re important were the results observed in the patient with blepharospasm.

In this case, capsaicin produced vision improvement astonishingly similar to that described in another patient with blepharospasm who received nicotine spray ${ }^{8}$. However, we went further that this latter report in demonstrating visual function improvement because we used the three minutes reading test ${ }^{9}$ as well as the SRS ${ }^{13}$ both of which define severity and functional health in blepharospasm patients. It should be stressed that blinking rate scales might not be useful to test patients with focal dystonia affecting eye muscles because, sometimes, the forceful eyelid contractions detected, the less blinking rate will be registered.

Capsaicin acts on C-fibers, mostly polymodal nociceptors, exerting its main electrophysiological effects on sodium and calcium conductance with a subsequent potassium and perhaps chloride conductance modification leading it to secondary cellular hyperpolarization ${ }^{10}$. These cellular changes a re detected as modifications of the ultranociceptive response (R3) of electrically elicited the blink reflex $^{10}$, which is due to C-fibers activation presents in human trigemino-facial pathways ${ }^{7,9,10}$.

Recent studies also showed that capsaicin modifies presynaptic inhibition of low threshold afferents $^{15}$, a mechanism involved in modulation of R2 
responses of the blink reflex ${ }^{16}$. If so, capsaicin would deactivate the pathological A-to-C fibers cross talk ${ }^{17}$, originated by the repetitive noxious afferent stimuli on trigeminal nerves well known to occur in blepharospasm, with further plastic changes in the central sensori-motor program involving the socalled blinking generator ${ }^{18}$, leading to produce the vision improvement of our patient as shown here.

Such changes on sensory inputs might further modulate motoneurons's firing involved with the supraspinal motor control of facial muscles, similarly as nicotine and botulinum toxin injection does ${ }^{8}$ ${ }^{11}$. Further investigations in bigger populations using this neuro pha rmacological approach along with supportive neurophysiologic studies is worth of trying to gain a better understanding on the neurobiology of not only normal blinking but also sensorimotor dysfunctions as suggested elsewhere ${ }^{8}$.

\section{REFERENCES}

1. van der Post J, de Waal PP, de Kam ML, et al. No evidence of the usefulness of eye blinking as a marker for central dopaminergic activity. J Psychopharmacol 2004;18:109-114.

2. Bacher LF, Smotherman WP. Spontaneous eye blinking in human infants: a review. Dev Psychobiol 2004;44:95-102.

3. Schicatano EJ, Basso MA, Evinger C. Animal model explains the origins of the cranial dystonia benign essential blepharospasm. J Neurophysiol 1997;77:2842-2846.
4. Saito S, Moller AR. Chronic electrical stimulation of the facial nerve causes signs of facial nucleus hypersensitivity. Neurol Res 1993;15:225-231.

5. Leon-S FE, Arimura K, Chavez AM. A re-evaluation of the mechanism of action of botulinum toxin in facial movement disorders of man. Med Hypoth 1998;51:305-307.

6. Leon-S FE, Arimura K, Osame M. Three silent periods in the orbiculari oculi reflex of man: normal findings and some clinical vignettes. Electromyogr Clin Neurophysiol 2001;41:393-400.

7. Leon-Sarmiento FE, Bayona-Prieto J, Gomez J. Neurophysiology of blepharospasm and multiple system atrophy: clues to its pathophysiology. Parkinson Rel Dis 2005;11:199-201.

8. Dursun SM, Hewitt S, King AL, et al. Treatment of blepharospasm with nicotine nasal spray. Lancet 1996;348: 60

9. Leon-S FE, Suwazono S, Takenaga S, et al. The effects of tobacco smoking on the short, middle and long latency responses of the blink reflex in humans. J Clin Neurophysiol 1997;14:144-149.

10. Leon-S FE, Chavez AM. Selective inhibition of ipsilateral and contralateral R3 of the blink reflex by capsaicin. Muscle Nerve 1997;20:1606-1607.

11. Leon-S FE, Arimura K, Suwazono S, et al. The effects of shounousui on the three responses of the blink reflex in man. Muscle Nerve 1997;20:110-112

12. Defazio G, Lepore V, Abbruzzese G, et al. Reliability among neurologist in the severity assessment of blepharospasm and oromandibular dystonia: a multicenter study. Mov Dis 1994;9:616-621.

13. Lindeboom R, De Haan R, Aramideh M, et al. The blepharospasm disability scale: an instrument for the assessment of functional health in blepharospasm. Mov Dis 1995;10:444-449.

14. Basso MA, Strecker RE, Evinger C. Midbrain 6-hydroxydopamine lesions modulate blink reflex excitability. Exp Brain Res 1993;94:88-96.

15. Magerl W, Treede RD. Secondary tactile hypoesthesia: a novel type of pain-induced somatosensory plasticity in human subjects. Neurosci Lett 2004;361:136-139.

16. Rossi A, Scarpini C. Evidence for presynaptic inhibition on trigeminal primary afferent fibres in humans. J Neurol Neurosurg Psychiatry 1993;56:424-425.

17. Amir R, Devor M. Functional cross-excitation between afferent A- and C-neurons in dorsal root ganglia. Neuroscience 2000;95:189-195.

18. Trigo JA, Gruart A. Fisiología del sistema motor del parpado. Rev Neurol (Barc) 2001;32:755-761. 